\title{
Failure to avoid impending collision by the golden hamster (Mesocricetus auratus)
}

\author{
RICHARD R. ROSINSKI \\ University of Pittsburgh, Pittsburgh, Pennsylvania 15260 \\ and \\ JOHN J. KESELICA \\ Sarah Lawrence College, Bronxville, New York 10708
}

\begin{abstract}
Three experimental situations were used to assess the ability of the golden hamster to avoid collision with an approaching object. In all three situations (one optical loom and two real looms), the animals did not avoid the looming stimulus. Any responses that were made would not have resulted in successful avoidance of an approaching object. The golden hamster lacks the ability to avoid optically specified impending collision.
\end{abstract}

The perception of impending collision and the ability to avoid a rapidly approaching object is of clear survival value to an organism. Perception of imminent collision is possible on the basis of optical changes that are projected to the eye of an organism.

Gibson, Olum, and Rosenblatt (1955) have shown that the patterns of angular velocities (motion perspective) visually available to a moving organism potentially specify the distance of a point from the organism and the velocity of the observer. In addition, motion perspective specifies the rate of approach of an object, time to collision with an object, and path of approach of an object relative to a stationary organism. Gibson (1958) has argued that such information is of crucial importance in the behavioral ecology of an organism since it provides the animal with a basis for capturing food, avoiding a predator, and locomoting around obstacles.

Many investigators (Ball \& Tronick, 1971; Bower, Broughton, \& Moore, 1971; Schiff, 1965; Tronick, 1967) have demonstrated that optical information which specifies a looming object is used by human infants, chicks, rhesus infants, frogs, and crabs to avoid impending collision. The pickup of this information is specific enough to allow these animals to distinguish between a receding object, an approaching object on a collision course, and an approaching object on a noncollision course. Since in the normal ecology of the animal, these events may signify an attacking predator, the ability to pick up visual information for collision and respond appropriately may have greater biological significance. Furthermore, the ability to avoid imminent collision is so important that it is apparently little

Alexander W. Siegel sponsors this paper and takes full editorial responsibility for it. affected by specific experience. For example, Bower, Broughton, and Moore (1971) found that 6-day-old human neonates showed a pronounced avoidance response to looming. Hein, Gower, and Diamond (1970) found that kittens deprived of visual experience by being reared in diffuse light for 4 weeks showed triggered extension of the forepaws to impending collision with a surface. And, Schiff, Caviness, and Gibson (1962) found that avoidance responses to optically specified collision did not habituate over repeated presentations.

\section{METHOD}

Eight adult male golden hamsters (Mesocricetus auratus) were used as subjects in three different situations to determine the loom avoidance ability of the animals. Schiff (Note 1) has suggested that loom avoidance behavior may depend in part on the amount or kind of stimulus information provided in an experimental situation. Species (e.g., frogs) that avoid $50 \%$ $60 \%$ of the time when collision is specified only by optical magnification of an object's contours respond $100 \%$ of the time when other information for collision is available. Consequently, an optical loom and two varieties of real loom were used with each animal to determine whether different stimulus situations would affect avoidance behavior. All testing was done in the laboratory during the early evening (6:00-8:00 p.m.).

\section{Optical Loom}

In the optical loom condition, a $10-\mathrm{W}$ point source projector was positioned horizontally $61 \mathrm{~cm}$ behind a $46 \times 46 \mathrm{~cm}$ rearprojection screen. Each subject was positioned $61 \mathrm{~cm}$ in front of the screen so that the pattern of optical magnification on the screen was identical to that provided by an approaching object. To assure that the subject remained at the appropriate station point, the animal was restrained in a circular cage, $20.3 \mathrm{~cm}$ in diam and $12.7 \mathrm{~cm}$ in height, made of $1.2-\mathrm{cm}$ galvanized mesh. Looming occurred only when the subject was facing the screen. The projective looming was accomplished by moving a $3.8-\mathrm{cm}$ sphere from the screen toward the point source. The sphere was moved manually on a straight track so that the projected size increased from minimum to maximum in $1 \mathrm{sec}$ and so that the pattern of magnification was symmetrical and specified collision. Five trials were run with each subject. 


\section{Real Loom 1}

In the first real loom condition, the restraining cage was placed on the floor and the top of the cage was replaced by a $30.4 \times 30.4 \times .6 \mathrm{~cm}$ sheet of Plexiglas to eliminate air currents and other nonvisual information. A $20.3 \times 20.3 \mathrm{~cm}$ textured acoustical tile was dropped approximately $2.7 \mathrm{~m}$ directly onto the subject. The tile was attached to the ceiling by thin Dacron strings so that it stopped $1.2 \mathrm{~cm}$ above the Plexiglas. Looming was initiated only when the subject was standing on its hind legs and looking upward. The tile square fell freely. Five trials were run with each subject.

\section{Real Loom 2}

In the second real loom condition, a $3.8-\mathrm{cm}$ rubber ball was hung from a $1.8-\mathrm{m}$ Dacron cord and swung so that, at the lowest point in its trajectory (X), it passed about $2.5 \mathrm{~cm}$ from the floor. Each subject was released freely on the floor and, as it approached $\mathrm{X}$, the ball was released. Under these conditions, if the subject did not avoid the loom, it was struck on the head by the rubber ball. Two trials were run with each subject. Within each situation, testing was completed in a single day, with 2 days elapsing between test situations.

\section{RESULTS AND DISCUSSION}

On the optical loom and first real loom tasks, subjects' responses were categorized as no response, orienting, or avoiding. Crouching was counted as an avoidance response although such a response would not have resulted in successfal avoidance of an approaching predator.

In the optical loom situation, 40 trials were run. No response was given in $52.5 \%$ of the trials. Orienting was observed in $40 \%$ of the trials. Avoiding occurred in $7.5 \%$ of the trials. In all the avoidance responses, subjects simply crouched. In the 40 trials of Real Loom 1, no response was made on $62.5 \%$ of the trials. Orienting was observed in $7.5 \%$ of the trials. Avoiding was observed on $30 \%$ of the trials. All avoiding responses consisted of crouching. In the 16 trials of Real Loom 2 , all subjects on all trials were hit by the rubber ball. No successful avoidances occurred. None of the subjects, on any trial in any of the experimental situations, attempted to move out of the path of the approaching object.

It is clear from the three types of situations used in the present experiment that the golden hamster does not avoid visually specified collision with an approaching object. This conclusion holds whether avoidance is based on projected-size magnification (optical loom); on projected-size magnification, internal-texture magnification, and progressive background occlusion (Real Loom 1); or on a combination of visual and nonvisual information (Real Loom 2). Although responses to looming were observed, in none of the three situations did the subjects make responses which would have resulted in successful avoidance of an attacking predator. Most responses could be classified as orienting or freezing, behaviors which occur to many sudden or novel stimulus events in visual as well as nonvisual modalities.
Such responses might be adaptive in avoiding a searching predator, but they would be of no use once an attack had been initiated and collision was imminent. To our knowledge, this is the only species ever tested that does not avoid visual specified impending collision.

The fact that the animals did orient to the stimuli and that previous research (Keselica \& Rosinski, Note 2) has shown that hamsters are capable of using motion perspective information suggests that they are capable of registering the stimulus changes that specify looming. It appears, however, that these stimulus changes carry no effective information for the golden hamster and do not control avoidance behavior. This indicates a specific deficit in visual-motor integration. Although orienting to the stimulus was observed on some trials, registerable gradients of motion perspective did not elicit successful avoidance of a potentially dangerous object.

Whether this deficit is the result of an adaptation to its nocturnal environment or the result of the extensive inbreeding of the laboratory strain of the golden hamster cannot be determined. However, it is clear that the stimulus changes associated with looming carry no meaning for the animal. Optical expansion of contours and textures do not elicit avoidance of impending collision by the hamster.

\section{REFERENCE NOTES}

1. Schiff, W. Personal communication, 1969.

2. Keselica, J. J., \& Rosinski, R. R. Collicular function in the spatial layout perception of the golden hamster. Paper presented at the meeting of the Eastern Psychological Association, Washington, D.C., May 1970.

\section{REFERENCES}

Ball, W., \& Tronick, E. Infant responses to impending collision: Optical and real. Science, 1971, 171, 818-820.

Bower, T. G. R., Broughton, J. M., \& Moore, M. K. Infant responses to, approaching objects: An indicator of response to distal variables. Perception \& Psychophysics, 1971, 9, 193-196.

GibsoN, J. J. Visually controlled locomotion and visual orientation in animals. British Journal of Psychology, $1958,49,182-194$.

Gibson, J. J., Olum, P., \& Rosenblatt, F. Parallax and perspective during aircraft landings. American Journal of Psychology, 1955, 68, 372-385.

Hein, A., Gower, E. C., \& Diamond, R. M. Exposure requirements for developing the triggered component of the visual-placing response. Journal of Comparative and Physiological Psychology, 1970, 73, 188-192.

Schiff, W. Perception of impending collision: A study of visually directed avoidance behavior. Psychological Monographs, 1965, 79(11, Whole No. 604).

Schiff, W., Caviness, J. A., \& Gibson, J. J. Persistent fear responses in rhesus monkeys to the optical stimulus of “looming." Science, 1962, 136, 982-983.

Tronick, E. Approach response of domestic chicks to an optical display. Journal of Comparative and Physiological Psychology, 1967, 64, 529-531.

(Received for publication August 30, 1976.) 